\title{
IMAGINÁRIO FORMAL E IMAGINÁRIOS REAIS SOBRE A DEFINIÇÃO DE DESASTRES NO BRASIL
}

\author{
FORMAL AND REAL IMAGINARIES ABOUT THE DEFINITION OF \\ DISASTERS IN BRAZIL
}

\author{
Ricardo Silva Gama ${ }^{1}$ \\ Envio: 15 set. 2011. \\ Aceitação: 15 mar. 2012.
}

\begin{abstract}
RESUMO
O que é um desastre na visão do poder público e das comunidades atingidas, no Brasil do início do século XXI? Este é o problema ao qual se procura resposta aproximativa no estudo. Para tanto, partiu-se da hipótese de que o imaginário formal não é capaz de apreender a significação dos desastres no Brasil, devendo ser complementado pelos imaginários reais das coletividades atingidas por essas ocorrências. Para comprovar ou refutar a hipótese, buscou-se a análise do imaginário formal sobre a definição de desastre nas normativas que compreendem a gestão do Sistema Nacional de Defesa Civil no Brasil, passando-se, a seguir, para a perquirição dos indicadores das ciências sociais referentes aos imaginários reais sobre os desastres no Brasil e na América Latina. Pode-se verificar, por meio dos dados e marcos teóricos utilizados, que há dissociação entre imaginário formal e os diversos imaginários locais advindos das populações sujeitas à vulnerabilidade. Um caminho com possibilidades de ser trilhado neste campo compreende o diálogo entre os saberes que influenciam estilos diferenciados de organização e práticas de uso dos recursos, suficiente para o caracterizar como ferramenta para minimização de riscos e da vulnerabilidade.
\end{abstract}

Palavras-chave: Desastres. Imaginário. Brasil.

\begin{abstract}
What is a disaster to government and damaged communities in Brazil in the beginning of the 21st century? This study tries to answer this question. The hypothesis established for the study is that formal imaginary is not enough to apprehend the meanings of disasters in Brazil, therefore it must be complemented by the real imaginaries emergent from the damaged communities. To confront or refute the hypothesis an analysis of formal imaginary present in the definitions of disaster in the National System of Civil Defense in Brazil were studied. Next, elements
\end{abstract}

${ }^{1}$ Mestre em ciências sociais aplicadas (Universidade Estadual de Ponta Grossa - UEPG); doutorando em sociologia pela Universidade Federal do Paraná. <ricardo0gama@hotmail.com> 
from the social sciences related to the real imaginaries about disasters in Brazil and Latin America were investigated. It was verified, based on data and theoretical elements used in the studied, the dissociation between formal imaginary and the diversity of real local imaginaries from the vulnerable population. A possible path in this case, includes the dialogue between the knowledge that influence different styles of organization and practices in the use of resources enough to characterize it as a tool to minimize the risks of vulnerability.

Keywords: Disasters. Imaginary. Brazil.

\section{Introdução e aspectos metodológicos}

O que é um desastre na visão do poder público e das comunidades atingidas, no Brasil do início do século XXI? Este é o problema de pesquisa ao qual se procura dar resposta aproximativa neste estudo. Para tanto, partiu-se da hipótese - formulada com base em dados preliminares - de que o imaginário formal (propagado pelas instituições públicas competentes) não é suficientemente capaz de apreender a significação dos desastres no Brasil, devendo ser complementado pelos imaginários reais das coletividades humanas atingidas por essas ocorrências.

Desdobrada a hipótese, tomou-se como base para sua confrontação a mediação das variáveis abaixo.

- Para identificar o imaginário formal referente aos desastres, procurou-se a sua caracterização na ordem institucional e jurídica formal, oficialmente estabelecida no âmbito da União pela Lei 12.340/2010, regulamentada pelo Decreto 7.257/2010, atos que não podem ser contrariados por normas estaduais e municipais.

- Para identificar se os imaginários reais das coletividades humanas atingidas pelos desastres diferem e/ou complementam o posicionamento formal, é prudente levantar os estudos acerca da aproximação das ciências sociais em relação ao tema dos desastres, no objetivo de obter indicação de situações em que os imaginários reais pudessem gerar saberes importantes à coletividade, não previstos nas definições oficiais. Os dados necessários foram colhidos mediante levantamento da literatura especializada (com foco no caso do Brasil e da América Latina), de informações disponibilizadas pelo poder público e a sociedade civil, além de observação em campo, procedida em sobrevoo realizado no dia 18 de março de 2011 (uma semana após a deflagração das enchentes e escorregamentos) e três visitas para observação das áreas atingidas por escorregamentos durante as chuvas do mês de março de 2011, no litoral paranaense, especialmente no município de Morretes, realizadas entre os meses de março e julho de 2011.

$\mathrm{Na}$ intenção de comprovar ou refutar a hipótese, busca-se, primeiramente, a apresentação e a análise do imaginário formal sobre a definição de desastre nas normativas que compreendem a gestão do Sistema Nacional de Defesa Civil (Sindec), passando-se, a seguir, para a perquirição dos indicadores das ciências sociais referentes aos imaginários reais sobre os desastres no Brasil e na América Latina.

Posteriormente, é promovida uma discussão acerca das possibilidades de diálogo horizontal entre os saberes formais e não formais para uma integração que possibilite enriquecer o olhar das ciências sociais sobre o tema dos desastres, o que representa um verdadeiro confrontamento da hipótese (e da problemática que lhe dá suporte) com os dados colhidos na aproximação procedida durante o processo de pesquisa.

Partiu-se, para elaboração do trabalho, da perspectiva da atividade científica voltada para aproximação de uma realidade complexa, multifacetada e não linear, com relação à qual não se admite simples relação de causa e efeito (MORIN, 2000). Resulta do pensamento complexo que a realidade se constitui de processos dinâmicos, orgânicos, cuja fluência decorre da interação de sujeitos e objetos, de modo dialógico, sem o seu afastamento pelo conhecimento (DALLA VECCHIA, 2008, p. 157). Afina-se o estudo ao entendimento de que não há referência 
absoluta às aproximações da realidade, encontrando-se os sujeitos imersos em uma recursividade contínua de interações para esta finalidade, não explicável pela abordagem representacionista (MATURANA; VARELA, 2007).

Os problemas ambientais, dentre os quais se inserem os desastres com esses efeitos, compreendem sistemas complexos "nos quais intervêm processos de diferentes racionalidades, ordens de materialidade e escalas espaçotemporais" (LEFF, 2000, p. 20), pelo que se pode asseverar que este campo é constituído das interconexões entre humanos e não humanos e seu conhecimento exige abordagem integralista e investigação multidisciplinar, as quais permitam conexão das ciências naturais e sociais, bem como das esferas do dever ser e do material, da economia, da tecnologia e da cultura.

A isso se agrega a necessidade de colaboração entre as esferas do conhecimento, no que alude tanto às disciplinas acadêmicas como às práticas não científicas (LEFF, 2000), elementos que tendem a representar, não sem exceções, o imaginário formal e os imaginários reais no caso dos desastres.

\section{O desastre formal}

O imaginário formal das instituições autorizadas a limitar a atuação dos coletivos humanos representa a vontade objetiva institucionalmente legitimada perante a sociedade. Toma corpo e forma, no caso do Brasil, através da Lei 12.340/2010, regulamentada pelo Decreto 7.257/2010, ato normativo ao qual foi outorgado o poder para definir o que é desastre para a República Federativa do Brasil. Ou seja, no Brasil, quem definiu o que é desastre foi um ato regulamentar de competência do presidente da república, na forma do artigo 84 , IV, da Constituição Federal de 1988.

Sob o foco do Estado brasileiro, o desastre representa o "resultado de eventos adversos, naturais ou provocados pelo homem sobre um ecossistema vulnerável, causando danos humanos, materiais ou ambientais e consequentes prejuízos econômicos e sociais".

Trata-se, aparentemente, de uma definição aceitável dentro do ponto de vista científico, que prevê a possível origem dos desastres como natural (relativa aos coletivos não humanos) ou antrópica, bem como a noção de vulnerabilidade (atribuída equivocadamente aos não humanos e não às populações), que, conjugada à ocorrência, acarreta danos aos coletivos humanos e não humanos.

Pode-se mencionar que o estudo das catástrofes ambientais, especialmente nos países do Sul, de modo geral, tem privilegiado enfoques do tipo finalístico e estrutural - com suporte nas ciências naturais e nas engenharias -, minimizando os possíveis aportes das ciências sociais e enfrentando os desastres como eventos temporal e territorialmente deslocados (THOMAS, 1992, p. 74), cuja causalidade principal é derivada de processos físicos e naturais (HEWITT, 1983).

Mesmo diante da consideração da vulnerabilidade e dos prejuízos ambientais, econômicos e sociais, o imaginário formal porta características que o aproximam da lógica identitária-conjuntiva (CASTORIADIS, 2007, p. 405), haja vista sua aproximação das ciências (e racionalidade) modernas, valorizando a imposição da visão técnica. Por vezes, vincula-se a aspectos funcionais e instrumentais operacionalizados pela linguagem, insuficientes para transmitir aos possíveis atores de interesse o valor simbólico e imaginário das catástrofes e dos efeitos deixados.

Esta racionalidade foi formulada a partir de visões dos não humanos como locus de exterioridade (e inferioridade), significativos de ameaça e fonte de recursos (SANTOS 2008), devendo ser objeto de transformação tecnoeconômica (LEFF, 2000). Tal lógica de relação com os não humanos desemboca em uma crise ambiental e de paradigma de projeto de sociedade, mostrando-se insustentável a sua exploração como mero meio de obtenção de riqueza (SANTOS 2008, p. 189), convertendo-os de suporte da vida para fonte de matéria-prima (LEFF, 2000).

Adicionalmente, no estrato simbólico, cabe resgatar que as catástrofes estão incorporadas às representações midiáticas, de modo tanto informativo quanto revelador de imaginários coletivos emergentes (IMBERT, 2002). E sua função principal como espetáculo de massa é dar ampla visibilidade ao caos global frente às alternativas da ideologia fatalista veiculada pelo discurso hegemônico (STENGERS, 2009), domesticando a desordem e integrando-a a um relato, mediante certa homogeneização que a torna aceitável e consumível (IMBERT, 2002). Assim, sob o foco da racionalidade sustentada na lógica 
identitária-conjuntiva, nada se pode fazer em relação às catástrofes, já que se são eventos “da natureza”, externos à razão.

\section{Desastre e os múltiplos imaginários reais}

Faz algum tempo que o próprio modelo conceitual de desastre trazido pelo imaginário formal no Brasil é objeto de crítica, decorrente da sua revisitada visão trazida pelas ciências sociais a partir da década de 1980 (v. HEWITT, 1983). Os desastres hoje não são vistos como resultado de eventos adversos, mas sim como processos que revelam dinâmicas ecológicas e humanas, as quais se diluem diante da crescente vulnerabilidade de umas frente às outras. A década de 1980 e o início dos anos 1990 marcam um momento de atenção das ciências sociais para o tema dos desastres (THOMAS, 1992), aprofundando sua relação e interface com as questões ambientais, que passaram a integrar o crescente interesse da sociologia a partir de meados dos anos 1970 (LENZI, 2005).

Em geral, os impactos dessas ocasiões extremas têm causado severas alterações nas dinâmicas ecológicas, culturais e econômicas dos coletivos existentes nas suas áreas de influência, chegando ao limite da supressão de território e existência, como já ocorreu na pretérita (TADDEI, 2008) e na recente história brasileira, com os escorregamentos e enchentes na região de Itajaí, Ilhota e Blumenau, em Santa Catarina, em 2008, no estado do Rio de Janeiro em 2009 e 2011, e em Morretes e Antonina, no Paraná, também no ano de 2011.

Utilizando a base conceitual desenvolvida por Thomas (1992), pode-se afirmar que os desastres representam fenômenos de mudança coletiva, os quais englobam ocorrências extremas e quotidianas, com causalidades sócio-históricas e físico-naturais, geradoras de impacto negativo nos âmbitos humano e não humano. Não se trata de processo anormal no que diz respeito ao seu conteúdo ou impacto, mas sim da concretização de um estado particular de normalidade das sociedades que subsistem em conjunturas limítrofes (THOMAS). Nesses termos, o desastre consiste em:

[...] uma ocasião de crise ou estresse social, observável no tempo e no espaço, em que sociedades ou seus componentes (comunidades, regiões, etc.) sofrem danos ou perdas físicas e alterações em seu funcionamento rotineiro. Tanto as causas como as consequências dos desastres são produto de processos sociais que existem no interior da sociedade. (THOMAS, 1992, p. 80).

Estabelece-se assim um ponto de partida para uma relação mais próxima das ciências sociais com o estudo dos desastres, possibilitado pela análise de processos, estruturas e mudanças coletivas e sua relação com o desenvolvimento global e regional (THOMAS, 1993), principiologia apenas aparentemente incorporada pelo imaginário formal, representado pela Política Nacional de Defesa Civil, de 2010. Do ponto de vista das ciências sociais, a aplicação do termo desastre faz referência específica a uma ocorrência ou uma série delas que impactam o modo de funcionamento regular de uma sociedade. Trata-se, portanto, de processos provocados por uma série de fatores não humanos ou antrópicos, dentre os quais se fazem presentes, a título exemplificativo, terremotos, epidemias, inundações, furacões, erupções vulcânicas, explosões, incêndios e contaminações.

Ao trabalhar as racionalidades que envolvem a percepção do meio ambiente, Serres (1994) remete à impressão segundo a qual, no curso da história, a Terra - tomada como inimiga comum da humanidade -, de vitoriosa passa à condição de vítima. E "Vencido, o mundo vence-nos, finalmente." O espaço (não humanos) depende de tal maneira dos homens que a agitação daquele, afastando-se do equilíbrio, gera inquietação destes (SERRES, 1994). Nesta perspectiva, o aumento da intensidade dos impactos provocados pelos desastres constitui o ponto mais evidente de uma cadeia de relações estabelecidas entre humanos e não humanos, pois as atividades socioeconômicas transformam o ambiente, que as constrange em seguida (ALTVATER, 1995), o que demanda regulação, com o fim de se evitarem os excessos (STENGERS, 2009).

Não se pode perder de vista que, em regra, os dilemas ambientais dos países não centrais têm raízes históricas na indução de uma velocidade de apropriação e propagação de modelos sociais insustentáveis, que rompem mecanismos ecológicos e culturais locais e regionais (LEFF, 200, p. 20-21; OSTROM et al., 2009, p. 52) e a interação simbiogenética entre os sistemas humanos e não humanos (LEFF, 2000, p. 26), aprofundando a vulnerabilidade a que estão expostas as coletividades humanas. 
Como projeto de superação desta lógica, Santos (2008, p. 116-18) se apoia no que chama de sociologia das ausências e das emergências, invertendo a compreensão ocidental do mundo (SANTOS, 2008, p. 95), baseada na impotência (nada se pode fazer contra eventos externos à racionalidade - determinismo), na arrogância (autossuficiência - livre-arbítrio), na metonímica (única forma de racionalidade possível - reducionismo) e na proléptica (progressão histórica linear). A seu ver, a contração do presente promovida pela razão hegemônica esconde a maior parte da riqueza inesgotável das experiências sociais do mundo (SANTOS, 2008, p. 101), motivo pelo qual passa a ser confrontada pelas ideias de entropia e catástrofe, incorporadas pelas teorias da complexidade e do caos (SANTOS, 2008, p. 96).

Nesse sentido, a demanda social pode evoluir no sentido de crescente exigência em matéria de segurança e rejeitar cada vez mais o conceito de $f a$ talidade (GARBACCIO; PAGEAUX, 2009, p. 301), mediante uma ampliação simbólica dos saberes, práticas e agentes, de modo a maximizar a probabilidade de esperança em relação à de frustração (SANTOS, 2008, p. 118). Assim, a contração do futuro o torna escasso e merecedor de cuidado com relação às alternativas possíveis, que podem variar da esperança ao desastre (SANTOS, 2008, p. 118). E esta medida de transposição pressupõe que toda formação humana (social) desenvolve-se em relação com seu entorno, diretamente condicionado por práticas culturais (LEFF, 2000, p. 51-95; OSTROM et al., 2009, p. 56).

Em outra frente, aponta Jonas (2006, p. 229) que o presente reflete um tempo de abuso do homem sobre os coletivos não-humanos, tendente a causar a sua própria destruição e de toda a biosfera. Assim, formula-se um questionamento dirigido à percepção do perigo que nosso poder representa, em razão do que o homem passaria a manter com os não humanos uma relação de responsabilidade. No mesmo sentido se posiciona Serres (1994, p. 31) ao suscitar que, desde que passou a gerar impactos ambientais de consequências globais, a humanidade vive um reconfigurado pacto de responsabilidade com o planeta, ao que denomina contrato natural, elemento de minimização do risco gerado pelas intervenções humanas.

Desliza-se, assim, da certeza sobre a produção de objetos sem risco a uma incerteza das relações, manifestada pela destruição da ideia de natureza, ${ }^{2}$ com perturbação do ordenamento das classes de seres consagrados pela ciência, multiplicando conexões e variando sua importância relativa (LATOUR, 2004, p. 53-56).

Nesse contexto, a conotação de desastre, em sentido comum, reflete a procura da definição do inimigo, que no caso consiste nos coletivos não humanos, a partir do momento em que seu comportamento em face dos humanos foge ao que se define como um cenário de normalidade, com efeitos catastróficos para a economia e a cultura (COELHO, 2005, p. 219). Contudo, os desastres têm sido acentuados por uma série de fatores produzidos por causas ambientais e antropogênicas, como a industrialização, o crescimento populacional e a utilização intensiva de recursos ambientais (COELHO, 2005, p. 220), fato que revela ao menos uma parcial responsabilidade dos coletivos humanos pela intensificação da sua ocorrência e dos seus efeitos, o que imputa a estes atores responsabilidade pelo desenvolvimento de capacidades coletivas de resposta (STENGERS, 2009).

Aproximando a discussão sociológica sobre o tema dos desastres aos imaginários reais dos coletivos humanos afetados por seus efeitos, pode-se apontar que a resposta a um desastre, via de regra, conjuga iniciativas de diversos setores da sociedade civil e do poder público, sem deixar de passar pelas comunidades atingidas.

As potenciais "comunidades atingidas" são as populações situadas em determinado território, encontrando-se em condição de vulnerabilidade frente $^{3}$ a ocorrências desastrosas de origem natural e antrópica, cuja diferenciação interna influencia diretamente a caracterização e a extensão dos danos sofridos pelas mesmas (THOMAS, 1992, p. 78). Segundo consta até o momento (MATTEDI; BUTZKE, 2001, p. 8), a experiência autoriza a identificação de quatro padrões principais de conduta social de resposta ao desastre, que vão desde a passividade na absorção dos efeitos o que permite deduzir a falta de consciência do risco, elevando a vulnerabilidade - até o estabelecimento de uma nova relação de ocupação e uso do solo e dos

\footnotetext{
${ }^{2}$ Sobre a construção e objetivação da divisão política entre sociedade e natureza, v. Latour (2004, p. 107).

${ }^{3}$ Suscetibilidade a perigo ou dano (BRAUCH, 2005), que pode ser de natureza física, econômica, social, política, técnica, ideológica, cultural, educativa, ecológica e institucional (WILCHES CHAUX, 1988).
} 
bens ambientais, reveladora de uma política de prevenção pensada em longo prazo. É importante mencionar ainda o pensamento de Drabeck (1986), para quem as respostas aos desastres apresentam uma dimensão temporal e outra estrutural, sendo que, em relação à dimensão temporal, as respostas podem ser divididas em quatro etapas, não necessariamente sucessivas e desvinculadas:

- preparação, que abrange as atividades de planejamento, previsão e prevenção;

- reação, eu se refere às atividades de mobilização imediatamente antes e ações de emergência imediatamente depois;

- recuperação, que compreende as medidas de restauração e de reconstrução; e

- mitigação, ou medidas que alteram a percepção do fenômeno e do ajustamento de longo prazo.

Contudo, acredita-se que as coletividades sofredoras dos efeitos das ocorrências desastrosas não devem contar somente com sua própria sorte. Parte-se do pressuposto de que elas esperam alguma atuação do poder público e da sociedade civil (ou das instituições e coletivos humanos) nos momentos de infortúnio. Ocorre que, em geral, os países do Sul encontram-se fragilizados em relação à resposta aos desastres - informada por fatores de contexto e opções políticas -, sendo pois carentes de quadros, meios e rotinas para atender às questões de segurança das comunidades em face de uma ocorrência desta natureza (COELHO, 2005, p. 222). Isso tem levado os referidos Estados, incluindo o Brasil (conforme os registros históricos já mencionados e a análise das ocorrências recentes), a preocupar-se muito mais com a gestão dos desastres que com a adoção de medidas preventivas aos seus efeitos, o que abre caminho para captação de recursos mais significativos junto aos entes internacionais, criando aparência de uma resposta mais eficaz, acentuando a marginalização da participação comunitária nesse cenário e, consequentemente, a utilização de seus saberes localmente construídos (COELHO, 2005, p. 233).

Persiste assim um campo de significações imaginárias e simbólicas, geneticamente vinculado aos conjuntos formados pelas populações impactadas, cujos integrantes são possuidores de propriedades comuns que os colocam em situação de vulnerabilidade, na medida em que os imaginários sociais criam uma realidade e conformam a identidade psíquica dos indivíduos (CASTORIADIS, 2007, p. 400).

Vislumbra-se nesse meio o divórcio entre o imaginário formal que sustenta intervenções externas e os múltiplos imaginários reais da população (MASKREY, 1994, p. 27), os quais têm como ponto de apoio um fato natural que incita a instituição de significações, ontologicamente representadas em indivíduos, atos e objetos (CASTORIADIS, 2007, p. 268 e 401). Vê-se, dessa forma, que essas coletividades humanas instituem o mundo como seu mundo - suas representações e seu fazer social - por meio de significações particulares emergentes de um panorama social-histórico que faz ser, para uma sociedade dada, o copertencer de objetos, atos e indivíduos aparentemente heterogêneos (CASTORIADIS, 2007, p. 405-09).

A literatura especializada registra alguns exemplos do descompasso entre o imaginário formal e os imaginários reais, em que a ajuda oferecida não é aquela esperada pelas comunidades (MASKREY, 1994, p. 25), indicando, dentre outros, os seguintes casos:

- a implementação de políticas públicas, especialmente nos países não centrais, que elevaram os níveis de concentração populacional e acabaram por tornar esses ordenamentos mais vulneráveis a diversos tipos de desastre (COELHO, 2005, p. 240);

- a promoção de um verdadeiro combate aos saberes enraizados das comunidades locais (COELHO, 2005, p. 240);

- a criação de aparelhos centralizados para enfrentamento dos desastres, excluindo a possibilidade de participação social, especialmente das coletividades atingidas por seus efeitos (COELHO, 2005, p. 243-244);

- a reconstrução de casas após um terremoto em Alto Mayo, no Peru, em 1989, demonstrou que em raros casos a tecnologia proposta pelos agentes externos era apropriada à cultura das comunidades atingidas (MASKREY, 1994, p. 26);

- a liberação parcial do saldo do FGTS para os atingidos pelos desastres de 2010 (estado do Rio de Janeiro) e 2011 (Morretes, 
Paraná) em zonas serranas no Brasil gerou uma corrida para saque desses recursos por muitos sujeitos que não foram atingidos pelos escorregamentos e enchentes.

A maioria dos exemplos citados, referentes a situações registradas na América Latina e na África, ajustam-se facilmente à lógica de enfrentamento de ocorrências desastrosas no Brasil, onde também há um modelo centralizado de gerenciamento dos desastres (conformado pela Política Nacional de Defesa Civil), que despreza os saberes locais.

Em vista desse cenário, pode-se afirmar, em certa medida, que cada família e comunidade vive seu próprio desastre (e possui seu próprio imaginário), variando enormemente de região para região e em conformidade com os grupos sociais envolvidos (MASKREY, 1994, p. 27).

\section{Discussão e conclusões}

A hipótese que norteou a investigação tem o seguinte enunciado: o imaginário formal não é suficientemente capaz de apreender a significação dos desastres no Brasil, devendo ser complementado pelos imaginários reais das coletividades humanas atingidas por essas ocorrências.

$\mathrm{O}$ imaginário formal referente aos desastres foi identificado na ordem institucional e jurídica formal, oficialmente estabelecida no âmbito da União pela Lei 12.340/2010, regulamentada pelo Decreto 7.257/2010. Como visto, trata-se de expediente fortemente criticado no âmbito das ciências sociais, já que toma como pressuposto a prevalência do tecnicismo sobre os saberes locais.

Já com relação aos imaginários reais, buscaram-se elementos em estudos acerca da aproximação das ciências sociais ao tema dos desastres, sendo os dados utilizados colhidos mediante levantamento da literatura especializada, de informações disponibilizadas pelo poder público e a sociedade civil, além de observação em campo.

Como visto ao longo da argumentação que baliza o estudo, há uma dissociação entre imaginário formal (que sustenta intervenções externas) e os diversos imaginários locais, porém reais, advindos das populações sujeitas à vulnerabilidade. Esse desencontro encaminha ao fracasso a implementação de muitos programas de prevenção de desastres na
América Latina (MASKREY, 1994, p. 14), situação que não é identificada de maneira diversa no Brasil, onde também os diferentes grupos sociais manejam imaginários próprios com base em distintas leituras e percepções de tempo e espaço (MASKREY, 2004, p. 22). Nesse sentido, Hewitt (1996, p. 13-15) manifesta constatação de que, em geral, as respostas sociais consideradas pelas medidas oficiais de atendimento às emergências são levadas em consideração, enquanto as indicações locais são ignoradas ou trivializadas, em razão da influência do tecnicismo, consubstanciando uma "violência silenciosa". Exemplifica essa afirmativa o caso brasileiro, promovendo-se uma transformação social do papel de lideranças locais portadoras de conhecimento não formal em figuras folclóricas, destituídas de autoridade política (TADDEI, 2009, p. 331).

A aproximação e a abertura para imaginários reais podem se apoiar na sociologia das ausências e das emergências, invertendo a lógica da compreensão moderna do mundo, baseada nos binômios da impotência/prepotência, reducionismo/linearidade (SANTOS, 2008, p. 116-18). Um dos modos dessa mediação aproximativa é a contração do futuro, fazendo-o escasso e merecedor de cuidado com relação à rigorosa análise das alternativas possíveis - as quais podem ser colhidas mediante a conjugação da técnica com os saberes locais -, que podem variar da esperança ao desastre (SANTOS, 2008, p. 118).

E a contração do futuro pode contar, neste caso, com o diálogo entre os saberes baseados em diversas cosmovisões - expressivas da emergência do caráter próprio da cultura - que influenciam estilos culturais de organização e práticas de uso dos recursos (LEFF, 2000) com potencial para serem utilizados como ferramenta para minimização dos riscos e da vulnerabilidade.

Isso possibilita a construção de sistemas de saberes plurais, em que se articulam saberes científicos e não científicos para conformação de novas configurações de conhecimentos (SANTOS, 2005) que busquem compreender um modo mais adequado e equilibrado de relação das coletividades humanas com os não humanos. Nas palavras de Santos:

Não se trata de eliminar a distinção entre conhecimento técnico e não técnico, mas, antes, de a tornar mais complexa a partir do pressuposto de que a própria fronteira entre o técnico e o social é uma 
fronteira móvel, que deve ser redefinida em função da situação e do problema, através das contribuições de todos os atores envolvidos e, em particular, de todos os que terão de viver com as consequências das decisões que forem tomadas. (SANTOS, 2005, p. 52).

Em muitos casos, o prestígio da voz dos atingidos por uma calamidade ("vozes anônimas do sofrimento" - HEWITT, 1996, p. 15-16) leva ao conhecimento do cerne do problema e revela verdades que permaneciam ocultas, possibilitando a emergência de novas perspectivas que desafiam aquelas já estabelecidas. Os integrantes de comunidades atingidas por desastres raramente são vítimas passivas dessas ocorrências. Muitos desses atores se portam de maneira a oferecer resposta ativa e imediata à catástrofe, bem como se comprometem com ações humanitárias de longo prazo junto a suas comunidades (HEWITT, 1996, p. 17).

Como se vê, para os fins deste trabalho, encontra-se confirmada a hipótese suscitada inicialmente, podendo-se afirmar com relativa segurança e objetividade - de acordo com os dados e marcos teóricos que dão suporte à pesquisa - que o imaginário formal não é suficiente para se auferir a complexidade simbólica das significações das ocorrências desastrosas, devendo ser complementado pelos imaginários reais dos coletivos humanos em situação de vulnerabilidade, a fim de as medidas de prevenção, mitigação, resposta e recuperação serem implementadas e dimensionadas de maneira equilibrada.

Em resposta ao problema de pesquisa, suscita-se que um desastre, na visão do poder público no Brasil, pelo menos até o início da segunda década do século XXI, representa o "resultado de eventos adversos, naturais ou provocados pelo homem sobre um ecossistema vulnerável, causando danos humanos, materiais ou ambientais e consequentes prejuízos econômicos e sociais".

Essa definição positivada pelo ordenamento jurídico não revela, até este momento, similaridade com a concepção de desastre vislumbrada a partir dos imaginários locais, resgatados pelas ciências sociais, para quem os desastres configuram fenômenos de mudança coletiva e englobam ocorrências extremas e quotidianas com causalidades sócio-históricas e físico-naturais geradoras de impacto negativo no âmbito humano e não humano. Não se trata de processo anormal no que diz respeito ao seu conteúdo ou impacto, mas sim da concretização de um estado particular de normalidade (THOMAS, 1992, p. 79).

Um caminho com possibilidades de ser trilhado neste campo, visando ao avanço na sua compreensão, conta com o diálogo entre os saberes que influenciam estilos culturais diferenciados de organização e práticas de uso dos recursos (LEFF, 2000, p. 97) com potencial para serem utilizados como ferramentas para minimização de riscos e da vulnerabilidade.

\section{Referências}

ALTVATER, E. O preço da riqueza. São Paulo: Unesp, 1995.

CASTORIADIS, C. A instituição imaginária da sociedade. 6. ed. Rio de Janeiro: Paz e Terra, 2007.

COELHO, J. P. B. Estado, comunidades e calamidades naturais no Moçambique rural. In: SANTOS, B. S. (Org.). Semear outras soluções: os caminhos da biodiversidade e dos conhecimentos rivais. Rio de Janeiro: Civilização Brasileira, 2005, p. 217-51.

DALLA VECCHIA, A. M. Estruturas expressivas ou materiais do pensamento biocêntrico. Pensamento Biocêntrico, Pelotas, n. 10, p. 153-79, 2008.

DRABECK, T. E. Human system responses to disaster: an inventory of sociological findings. Nova York: SpringerVerlag, 1986.

GARBACCIO, G. L.; PAGEAUX, M. Visão europeia do direito das catástrofes. In: BENJAMIN, A. H.; LECEY, E.; CAPELLI, S. (Orgs.). Direito ambiental, mudanças climáticas e desastres: impactos nas cidades e patrimônio cultural. In: CONGRESSO INTERNACIONAL DE DIREITO AMBIENTAL, 13. Anais... v. 2. São Paulo: Imprensa Oficial, 2009.

HEWITT, K. The idea of calamity in a technocratic age. In: HEWITT, K. Interpretation of calamity. London: George Allen \& Unwin, 1983.

Daños ocultos y riesgos encubiertos: haciendo visible el espacio social de los desastres. In: MANSILLA, E. (Org.). Desastres: modelo para armar. Bogotá: La Red, 1996, p. 11-29.

IMBERT, G. Azar, conflicto, accidente, catástrofe: figuras arcaicas en el discurso posmoderno - entre lo eufórico y lo disfórico. Trama \& Fondo, Madri, n. 12, 2002, p. 19-30.

JONAS, H. O princípio responsabilidade: ensaio de uma ética da civilização tecnológica. Rio de Janeiro: Contraponto, 2006 . 
LATOUR, B. Políticas da natureza: como fazer ciência na democracia. Bauru: Edusc, 2004.

LEFF, E. Ecologia, capital e cultura: Racionalidade ambiental, democracia participativa e desenvolvimento sustentável. Blumenau: Edifurb, 2000.

LENZI, C. L. Sociologia ambiental: risco e sustentabilidade na modernidade. Bauru: Edusc, 2005.

MASKREY, A. Comunidad y desastres en América Latina: Estrategias de intervención. In: THOMS, A. L. Viviendo in riesgo: comunidades vulnerables y prevención de desastres en América Latina. Bogotá: La Red, 1994, p. 14-38.

MATTEDI, M. A.; BUTZKE, I. C. A relação entre o social e o natural nas abordagens de Hazards e de Desastres. Ambiente \& Sociedade, ano 4, n. 9, 2001.

MATURANA, H. R.; VARELA, F. J. A árvore do conhecimento: as bases biológicas da compreensão humana. 6. ed. São Paulo: Palas Athena, 2007.

MORIN, E. O pensamento complexo, um pensamento que pensa. In: .; LE MOIGNE, J. L. A inteligência da complexidade. São Paulo: Peirópolis, 2000.

OSTROM, E.; VANWEY, L. K.; MERETSKY, V. Teorias subjacentes ao estudo de interações homem-ambiente. In: MORAN, E.; OSTROM, E. (Orgs.). Ecossistemas florestais: interação homem-ambiente. São Paulo: Edusp, 2009. p. 41-81.

SANTOS, B. S. A gramática do tempo: para uma nova cultura política. 2. ed. São Paulo: Cortez, 2008.

.; MENESES, M. P G.; NUNES, J. A. Introdução: para ampliar o cânone da ciência: a diversidade epistemológica do mundo. In: SANTOS, B. S. (Org.). Semear outras soluções: os caminhos da biodiversidade e dos conhecimentos rivais. Rio de Janeiro: Civilização Brasileira, 2005. p. 21-121.

SERRES, M. O contrato natural. Lisboa: Instituto Piaget, 1994.

STENGERS, I. Au temps des catastrophes: résister à barbarie qui vient. Paris: La Découverte, 2009.

TADDEI, R. Oráculos de lluvia en tiempos modernos: medios, desarrollo económico y transformaciones de identidad social de los profetas del sertão en el nordeste de Brasil. In: ACOSTA, V. G. (Org.). Historia y desastres en América Latina. Bogotá: La Red, 2008, p. 331-52. v.3

THOMAS, A. L. Ciencias sociales e desastres naturales em America Latina: un encuentro inconcluso. Eure, Santiago, Chile v. 19, n. 58, p. 73-84, 1993. 